GRASAS Y ACEITES 65 (1)

January-March 2014, e013

ISSN-L: 0017-3495

doi: http://dx.doi.org/10.3989/gya.109413

\title{
Stability of rice bran oil extracted by SFE and soxhlet methods during accelerated shelf-life storage
}

\author{
A. Mariod ${ }^{\mathrm{a}, \mathrm{b}, \otimes}$, M. Ismail ${ }^{\mathrm{b}, \mathrm{c}, \varpi}$, N.F. Abd Rahman ${ }^{\mathrm{c}}$ and B. Matthaus ${ }^{\mathrm{d}}$ \\ aFaculty of Sciences and Arts-Alkamil, King Abdulaziz University, Alkamil-Saudi Arabia \\ ${ }^{b}$ Laboratory of Molecular BioMedicine, Insitute of Bioscience, Universiti Putra Malaysia, 43400 \\ UPM, Serdang, Selangor, Malaysia \\ ${ }^{c}$ Department of Nutrition and Dietetics, Faculty of Medicine and Health Sciences, Universiti Putra Malaysia, 43400 UPM, \\ Serdang, Selangor, Malaysia \\ ${ }^{\mathrm{d}}$ Department for Lipid Research, Max Rubner-Institute, Federal Research Institute for Nutrition and Food, Muenster, Germany \\ Corresponding authors: maznahis@putra.upm.edu.my; basitmariod@yahoo.com
}

Submitted: 17 October 2013; Accepted: 13 November 2013; Published on line: 13/02/2014

\begin{abstract}
SUMMARY: Supercritical fluid high oryzanol (SFE HO) and supercritical fluid low oryzanol (SFE LO) rice bran oils were obtained and compared with that extracted by the Soxhlet (SOX) method. Their composition and stability during storage were determined. The amount of unsaponifiable matter and gamma oryzanol of SFE samples were significantly $(\mathrm{p}<0.05)$ higher than SOX. While the amount of tocopherol in SOX $\left(4.0 \mathrm{mg} \cdot \mathrm{g}^{-1}\right)$ was higher than that reported in SFE HO and SFE LO, at 3.2 and $2.6 \mathrm{mg} \cdot \mathrm{g}^{-1}$, respectively. After storage for 42 days at $70{ }^{\circ} \mathrm{C}$ the $\mathrm{PV}, \mathrm{FFA} \%$, conjugated diene and $p$-anisidine values of SOX were higher than those of SFE HO, and SFE LO. The SFE samples showed better stability than SOX under successive heating and the addition of BHA decreased PV, FFA\%, conjugated diene and $p$-anisidine levels in all samples.
\end{abstract}

KEYWORDS: Oryzanol; Rice bran oil; Shelf life; Soxhlet; Stability; Supercritical fluid extraction; Tocopherol

RESUMEN: Estabilidad de aceites de salvado de arroz obtenidos mediante SFE y Soxhlet durante su vida útil en almacenamiento acelerado. Se realizaron extracciones mediante fluido supercrítico de salvado de arroz con alto (SFE HO) y bajo (SFE LO) contenido en orizanol y se comparó con los extraídos mediante Soxhlet (SOX). Se determinó la composición y la estabilidad durante el almacenamiento. La materia insaponificable y el gamma orizanol de las muestras SFE fueron significativamente más altas $(\mathrm{p}<0,05)$ que SOX. Mientras la cantidad de tocoferol en SOX $\left(4,0 \mathrm{mg} \cdot \mathrm{g}^{-1}\right)$ fue mayor que lo encontrado para SFE HO y SFE LO, 3,2 y 2,6 $\mathrm{mg} \cdot \mathrm{g}^{-1}$ respectivamente. Después de 42 días de almacenamiento a $70{ }^{\circ} \mathrm{C}$ los valores de PV, FFA \%, dienos conjugados y $p$-anisidina de SOX fueron mayores que los de SFE HO, y SFE LO. Las muestras SFE mostraron mejor estabilidad que SOX bajo calentamiento y la adición de BHA disminuyó el PV, FFA \%, dienos conjugados y los niveles de $p$-anisidina en todas las muestras.

PALABRAS CLAVE: Aceite de salvado de arroz; Caducidad; Estabilidad; Fluido supercrítico; Oryzanol; Soxhlet; Tocoferol

Citation/Cómo citar este artículo: Mariod A, Ismail M, Abd Rahman NF, Matthaus B. 2014. Stability of rice bran oil extracted by SFE and soxhlet methods during accelerated shelf life storage. Grasas Aceites 65 (1): e013. doi: http:/l dx.doi.org/10.3989/gya.109413

Copyright: (C) 2014 CSIC. This is an open-access article distributed under the terms of the Creative Commons Attribution-Non Commercial (by-nc) Spain 3.0 Licence. 


\section{INTRODUCTION}

Rice bran is produced from the outer layer of brown rice. It contains high valued protein, fat and nutritional dietary fiber. In addition to phytonutrients, rice bran contains vitamins and minerals (Chatha et al. 2006). Rice bran oil (RBO) is extracted from the inner husk of rice, and it is a uniquely rich source of commercially-important bioactive phytochemicals used in nutrition, pharmacy and cosmetics. Rice bran oil contains $4.2 \%$ unsaponifiable matter, which contains three different kinds of natural antioxidants of tocopherols, tocotrienols and oryzanol (Perretti et al., 2003). RBO contains a significantly high amount of $\mathrm{y}$ - oryzanol. This substance is composed of several kinds of ferulic acid esters of triterpene alcohols and plant sterols and has an effect similar to that of tocopherol (Anwar et al., 2005). Studies have proven that y-oryzanol possesses curative functions for many human diseases, including a cholesterol lowering effect which is beneficial to cardiovascular health (Cicero and Gaddi, 2001). Rice bran oil is notable for its very high smoke point of $254{ }^{\circ} \mathrm{C}$ and its mild flavor, making it suitable for high-temperature cooking methods such as stir frying and deep frying. Rice bran oil contains $40.5 \%$ monounsaturated fatty acids as oleic acid, $35.79 \%$ polyunsaturated as linoleic and linolenic acids, and $23.14 \%$ saturated as palmitic, myristic, and stearic acids (Mishra et al., 2012). In the literature, several authors have demonstrated the anti-oxidative effects of rice bran extracts (Iqbal et al., 2005; Nam et al., 2006), stabilized and unstabilized defatted rice bran extracts (Mariod et al., 2010), evaluating their antioxidant activity using different in vitro methods

Solvent extraction is the conventional method used for extracting lipids from rice bran. This extraction practice uses highly toxic and flammable solvents like hexanes, petroleum ether, and isopropanol. These solvents also have problems associated with waste disposal due to increased environmental concerns and regulations. Toxic solvent residues in the final food product are also of concern (Patel, 2005).

Supercritical fluid extraction (SFE) of lipids has received attention as an alternative method to organic solvent extraction and has been shown to be useful for extracting certain lipids. Apart from carbon dioxide's non-toxic and non-flammable nature, supercritical carbon dioxide extraction also offers the most important advantage of varying the extraction power of the solvent by changing operating conditions such as pressure, temperature and flow rate. This provides selective extraction and fractionation capabilities to the process (Patel, 2005). Carbon dioxide has a low critical temperature $\left(31^{\circ} \mathrm{C}\right)$ making this SFE solvent ideal for biological materials like rice bran because of the possible degradation of thermally-liable bioactive compounds at higher temperatures.

In Malaysia, rice is the main cereal that is consumed by the majority of its population. However, rice bran oil is still a new product in Malaysia, compared to several other countries such as Japan, India, Korea, China and Indonesia where rice bran oil is popular as a cooking oil. Rice bran oil actually has high potential availability in Malaysia and the research and development of rice bran oil is still in demand.

The nutritional and health qualities of rice bran oil have led researchers to be interested recognizing its oxidative stability. The oxidation of rice bran oil was evaluated after the addition of stabilized and unstabilized rice bran extracts (Mariod et al., 2010).

This study aims to determine the oxidative stability of rice bran oil extracted by Soxhlet in comparison with SFE rice bran oil fractions (high and low oryzanol) during accelerated shelf-life storage. The oxidative stability of SOX, SFE HO, SFE LO during accelerated shelf-life storage was determined and measured by peroxide value, free fatty acids, conjugated dienes, $p$-anisidine and thiobarbituric acid-reactive substances. The stability of SOX, SFE HO, SFE LO with and without BHA was also determined and compared.

\section{MATERIALS AND METHODS}

\subsection{Materials}

\subsubsection{Sample Material}

Rice bran was obtained from Bernas Rice Mills, Co. Tiram, Selangor, Malaysia. The rice bran samples were stabilized before the extraction process for $2 \mathrm{~min}$ at $2450 \mathrm{MHz}$, using a national microwave/ convection oven (model NN-C2003S, Matsushita Electric Industrial Co., Japan) (Mariod et al., 2010).

\subsubsection{Chemicals}

Methanol, acetonitrile, dicholoromethane, isopropanol, acetic acid, chloroform, isooctane, $p$-anisidine, 1-butanol, butylated hydroxyanisole (BHA), hexane, thiobarbituric acid, ethanol, sodium thiosulfate, ether, and phenolphthalein were of analytical and HPLC grade obtained from Fisher Scientific (Loughborough, LE, UK) and Merck (Darmstad, Germany).

Chemicals such as potassium hydroxide, sodium chloride and sodium methoxide were obtained from Sigma - Aldrich (St. Louis, MO, USA). The standard for unsaponifiable matter (tocopherol) and neutral lipids were purchased from Sigma Aldrich (St. Louis, MO, USA). The FAME reference standard was purchased from AccuStandard 
(New Haven, CT, USA). A pure standard of gammaoryzanol (Standard compounds of oryzanols, cycloartenyl ferulate and 24-methylene cycloartanyl ferulate) was obtained from Sigma Chemical Co. Ltd, Japan.

\subsubsection{Instruments}

The supercritical fluid extraction system was used (Thar Technologies, Pittsburgh, PA, USA, Laboratory Scale) with a rotary evaporator (Buchi, Flawil, Switzerland), universal and micro type centrifuge machine (Hettich Zentrifugen, Tuttlingen, Germany), ultrasonic water bath (HanShin, USA), and analytical balance (Shimadzu, Nakagyo $\mathrm{Ku}$, Kyoto, Japan). Each component of lipids in rice bran oil was determined using Agilent Technologies HPLC series 1200 (Santa Clara, CA, USA).

\subsection{Methods}

\subsubsection{SFE extraction of high oryzanol ( $\mathrm{HO})$ and low oryzanol ( $L O)$ RBOs.}

Supercritical fluid high oryzanol rice bran (SFE HO) and supercritical fluid low oryzanol rice bran (SFE LO) oils were extracted using SFE with different pressures and temperatures. In brief, carbon dioxide $\left(\mathrm{CO}_{2}\right)$ from a cylinder was pressurized and then fed into the solvent reservoir. Pressurized $\mathrm{CO}_{2}$ becomes the supercritical fluid by preheating in an equipped air-bath. After rice bran (180 g) was placed in the extractor, the supercritical fluid flowed into the extractor and mixed with rice bran. The extractor was connected to the collector vessel by a micro-metering valve. The temperature and pressure were controlled to obtain the SFE oil. After that the mixed solution of RBO and supercritical fluid from the extractor is depressurized and the $\mathrm{RBO}$ was collected (Bruhl and Matthaus, 1999). To obtain the HO from SFE the pressure was 600 bars and the temperature was $60{ }^{\circ} \mathrm{C}$. Meanwhile, to obtain the LO the pressure was 200 bars and temperature was $40{ }^{\circ} \mathrm{C}$. The flow rate and duration of time to extract $\mathrm{HO}$ and $\mathrm{LO}$ was similar with $25 \mathrm{~g} \cdot \mathrm{min}^{-1}$ of flow rate and 150 min duration of time.

\subsubsection{Soxhlet Extraction}

In brief, 100 grams of ground rice bran were weighed and equally divided into 4 extraction thimbles. Each thimble was then transferred into a soxhlet extractor. Approximately, $300 \mathrm{~mL}$ of $n$-hexane were added to the extraction flask, which were connected to the extractor and condenser. After extraction began, the solvent flow rate was manually adjusted to $7 \mathrm{~min} \cdot \mathrm{cycle}^{-1}$. Finally, the extraction process was terminated after 100 cycles. After extraction was complete, $n$-hexane was removed at $50{ }^{\circ} \mathrm{C}$ under reduced pressure using a rotary evaporator. The flasks were placed in a desiccator chamber for 1 hour. The obtained soxhlet oil (SOX) was weighed and the yield was calculated.

\subsubsection{Fractionation of lipids extracted by SFE and Soxhlet}

Lipids extracted by SFE and Soxhlet were fractionated on an Solid Phase Extraction (SPE) system using a pre-packed 1-g silica gel cartridge column (Sigma - Aldrich St. Louis, MO, USA). Although vacuum could be applied to increase the flow rate of the eluent, generally gravity alone was sufficient to provide adequate flow. Initially, the cartridges were conditioned with $5 \mathrm{~mL}$ of hexane, followed by $5 \mathrm{~mL}$ of $\mathrm{CHCl}_{3}$. The neutral lipid (NL), glycolipid (GL), and phospholipid (PL) fractions were successively eluted with $10 \mathrm{~mL}$ of $\mathrm{CHCl}_{3}$ and acetone $(4: 1, \mathrm{v} / \mathrm{v})$, $15 \mathrm{~mL}$ of acetone and methanol $(9: 1, \mathrm{v} / \mathrm{v})$, and 10 $\mathrm{mL}$ of methanol. The purity of the fractions was checked by TLC. Solvents from the fractions were rotary evaporated, transferred to recovery vials using the eluting solvents, and evaporated to dryness at $37^{\circ} \mathrm{C}$. The recovery of the lipids was $\approx 100 \%$. The amount of polar lipids was the sum of GL and PL (Hubbard et al., 2004).

\subsubsection{Unsaponifiable and wax contents}

Unsaponifiable and wax contents were measured following AOCS Da 11-42, and AOCS Ch 8-02 Methods, respectively (AOCS,1998).

\subsubsection{Fatty Acid Composition by Gas Liquid Chromatography (GLC)}

The fatty acid compositions of the RBOs were determined by GLC. The oils were converted to their corresponding methyl esters according to the AOCS Official Methods (1998). $\mathrm{BF}_{3} /$ methanol was used for methylation. The GLC analysis of the fatty acid methyl esters FAME was performed using a HewlettPackard HP-5890 Series II gas chromatograph equipped with an Ultra $2(25 \mathrm{~m} \times 0.32 \mathrm{~mm} \times 0.5 \mu \mathrm{m}$ film thickness of 5\% biphenyl and 95\% dimethyl polysiloxane; Hewlett-Packard, Waldron, Germany) equipped with a capillary column, a split injector (split ratio 88:1), and an FID. The column temperature program was $5 \mathrm{~min}$ at $150{ }^{\circ} \mathrm{C}, 10^{\circ} \mathrm{C} \cdot \mathrm{min}^{-1}$ to $275^{\circ} \mathrm{C}$, and $10 \mathrm{~min}$ at $275^{\circ} \mathrm{C}$. The injector and detector temperatures were 250 and $280^{\circ} \mathrm{C}$, respectively. The carrier gas was nitrogen at a flow rate of $1.6 \mathrm{~mL} \cdot \mathrm{min}^{-1}$. Air and hydrogen flow rates were 460 and $33 \mathrm{~mL} \cdot \mathrm{min}^{-1}$, respectively. The peaks of fatty acids were identified by comparing their retention times with those of a mixture of standard fatty acid 
methyl esters (Sigma Chemicals Co., Deisenhofen, Germany). Each fatty acid methyl ester sample was analyzed in duplicate.

\subsubsection{Quantification for $\gamma$-oryzanol}

Gamma oryzanol was quantified using a reversedphase HPLC. A C18 column and a diode-array ultraviolet-visible detector (Hewlett-Packard, San Fernando, CA) were employed in the HPLC system. The mobile phase consists of methanol, acetonitrile, dichloromethane, and acetic acid (50:44:3:3) by volume. The flow rate was controlled at $1.4 \mathrm{~mL} \cdot \mathrm{min}^{-1}$. The analytes were detected at $330 \mathrm{~nm}$. The samples were diluted with the mobile phase and analyzed. Peak identification was based on the comparison of retention time (RT) values with the authentic standards of cycloartenyl ferulate, 24-methylene cycloartanyl ferulate and a mixture of oryzanol standards. The total oryzanols were quantified based upon the peak area of 24-methylene cycloartanyl ferulate, the major oryzanol component in rice bran. The concentrations of individual components of $\gamma$-oryzanol were calculated and the concentration of $\gamma$-oryzanol was obtained by adding all individual components (Shahid et al., 2005, Renuka Devi and Arumughan, 2007).

\subsubsection{Quantification of Tocopherol Contents}

Tocopherols were measured by a reversed-phase HPLC system connected to a fluorescent detector at $E x=298 \mathrm{~nm}$ and $E m=328 \mathrm{~nm}$. A $2.1 \mathrm{~mm}$ narrowbore analytical column packed with 5-m ODS (C18) hypersil silica used for the separation of tocols. The mobile phase acetonitrile/methanol/isopropanol/ water (45:45:5:5 by volume), was programed to acetonitrile/methanol/isopropanol (50:45:5) for $10 \mathrm{~min}$. These conditions were maintained for $15 \mathrm{~min}$ before returning to the original conditions. The total HPLC run time was $26 \mathrm{~min}$. A fine separation was achieved for tocopherols but bands were broad for tocotrienols. The samples were quantified by comparing the retention times/peak areas with those of the obtained standards. The total tocopherol and tocotrienol contents were determined by summing up the $\alpha, \beta, \gamma$ and $\delta$ isomers (Shahid et al., 2005).

\subsubsection{Oxidative Stability of SFE and Soxhlet Rice Bran Oils}

For the oxidative stability studies, the antioxidant BHA $(0.02 \%)$ was added to separate the samples of SFE HO, SFE LO, and SOX based on the concentration of antioxidant used and represents the maximum added antioxidant levels used in foods $(0.02 \%)$. The antioxidant $(0.02 \mathrm{~g})$ was dissolved in $10 \mathrm{~mL}$ of ethanol and then added to $100 \mathrm{~g}$ of RBOs following the procedure of Mariod et al. (2006). The ethanol was then evaporated at $45^{\circ} \mathrm{C}$ for $15 \mathrm{~min}$ to avoid over-oxidation and to enable the antioxidants to thoroughly mix with the sample. Control samples contained ethanol without the addition of antioxidants. The oxidation process was accelerated using the procedure of Mariod et al. (2006) in which all the experimental RBO samples were placed in an oven in an ultrasonic water bath (Bandelin electronic, Berlin, Germany) at $70{ }^{\circ} \mathrm{C}$ with a stream of air (flow $1 \mathrm{~L} \cdot \mathrm{h}^{-1}$ ). Subsamples of the RBO were removed from the oven at $0,7,14,21,35$ and 42 days and stored at $4{ }^{\circ} \mathrm{C}$ overnight in a refrigerator until tested for oxidation. The oxidation was evaluated by determining the peroxide value, conjugated dienes, $p$-anisidine value and thiobarbituric acid reactive substances.

Determination of Peroxide Value. Peroxide value was determined following the AOCS official method Cd 8b-90 (AOCS, 1998).

Determination of p-anisidine Value. p-Anisidine value of the oil was analyzed according to the method of AOCS, (1998).

Determination of Conjugate Dienes. The conjugated dienes were determined following the AOCS official method Ti 1a-64 (1998). $10 \mathrm{~mL}$ of each sample were mixed with $10 \mathrm{~mL}$ of isooctane and the absorbance was read at 234 and $270 \mathrm{~nm}$ using cells of $1 \mathrm{~cm}$. Pure isooctane was used as reference. The conjugated dienes were calculated according to the following equation:

$$
\mathrm{CD} \text { value }=\mathrm{A} /(\mathrm{C} * \mathrm{I})
$$

Where $\mathrm{CD}=$ conjugated diene, $\mathrm{A}=$ absorbance at $234 \mathrm{~nm}, \mathrm{C}=$ concentration $\left(\mathrm{g} \cdot 100 \mathrm{~mL}^{-1}\right)$ and $\mathrm{I}=$ path length $(\mathrm{cm})$.

Determination of Thiobarbituric Acid-Reactive Substances (TBARS). TBARS were determined following the method of Shahidi et al. (2003), where each sample $(200 \mathrm{mg})$ was weighed into $25 \mathrm{ml}$ volumetric flask and then made up to the mark with 1-butanol (ACS grade) and mixed thoroughly. A $5.0 \mathrm{~mL}$ portion of this solution was transferred into a dry test tube, and a $5.0 \mathrm{~mL}$ of fresh TBA reagent (200 mg TBA in $100 \mathrm{~mL} 1$-butanol) were added to it. The tube was placed in a $95{ }^{\circ} \mathrm{C}$ water bath for $120 \mathrm{~min}$. The tube was cooled to room temperature and the absorbance of the solution was read at $532 \mathrm{~nm}$. The TBAR value was calculated as follows:

$$
\text { TBARS value }=(A * 0.415) / \mathrm{m}
$$

Where $\mathrm{A}=$ absorbance at $532 \mathrm{~nm}$ and $\mathrm{m}=$ sample weight.

\subsubsection{Measurement of Free Fatty Acids (FFA)}

Free fatty acids as oleic acid percentages in the oil samples, were determined using an alkali titration method according to AOCS (1998). 


\subsection{Statistical Analysis}

The analyses were performed with three replicates. The mean values and standard deviation (mean \pm SD) were calculated and tested using the Student's $t$-test. Statistical significance was accepted at a level of $p<0.05$. Statistical analysis of variance (ANOVA) was performed on all values using the statistical program Statgrafics ${ }^{\circledR}$ Statistical Graphics System version 4.0 (Statgraphics $\left.{ }^{\circledR} 1985-1989\right)$.

\section{RESULTS AND DISCUSSION}

\subsection{Lipid Composition of Rice Bran Oils}

Table 1 shows the lipid composition of the rice bran oils extracted by conventional Soxhlet and SFE methods. From this table, the amount of unsaponifiable matter in Soxhlet RBO was about $4.7 \%$ which was significantly $(\mathrm{p}<0.05)$ less than 8.2 and $5.2 \%$ in SFE HO and SFE LO, respectively. The amount of unsaponifiable matter in $\mathrm{HO}$ was estimated to be about two times higher than the Soxhlet method. The exposure of RBOs to air for a longer period of time causes the degradation of antioxidants which are abundant in the unsaponifiable matter (Duvernay et al., 2005). As seen in Table 1, the gamma oryzanol content was affected by the method of extraction significantly $(p<0.05)$ as the amount of SFE HO and LO were 7.7 and $6.3 \mathrm{mg} . \mathrm{g}^{-1}$, respectively, which was higher than the amount of gamma oryzanol extracted using the soxhlet method.

SFE and SOX extracted RBOs were analyzed for their tocopherol contents using the HPLC technique. The highest concentration of tocopherol was found in the sample of SOX $\left(4.0 \mathrm{mg} \cdot \mathrm{g}^{-1}\right)$ which was higher than 3.2 and $2.6 \mathrm{mg} \cdot \mathrm{g}^{-1}$ as reported in SFE $\mathrm{HO}$ and SFE LO, respectively as the concentration of tocopherol in rice bran oil was affected by the method of extraction. As shown in Table 1, the wax content of the three different extracted oils was significantly different $(p>0.05)$. The amount of wax in HO and LO was 0.45 and $0.47 \%$ oil, respectively, compared with the soxhlet RBO, where the amount of wax was $0.32 \%$, which was slightly lower than the RBOs extracted by SFE. This was supported by
Patel, (2005) who found that RBO extracted using the SFE method was high in waxes.

In Table 1, the lipid classes of the oil extracted using the SFE and Soxhlet methods are presented. In the NL class there was a significant difference between HO, LO and Soxhlet, the estimated amounts of NL in $\mathrm{HO}$ and LO were about $0.97 \pm 0.01$ and $0.95 \pm 0.01\left(\mathrm{~g} \cdot \mathrm{g}^{-1}\right)$ which were almost higher than $0.70 \pm 0.43$ as reported for neutral lipids in the Soxhlet RBO. However, in the glycolipid and phospholipid classes there was no significant difference in Soxhlet RBO compared with the oil extracted using SFE.

The RBO obtained under different conditions by SFE HO, SFE LO and SOX extractions had similar fatty acid compositions. From Table 2 it is clear that no significant differences were observed in the fatty acid compositions among the oils obtained by SFE HO, SFE LO and SOX extraction methods. These findings are in good agreement with those reported by Balachandran et al. (2008).

Using SFE, high oryzanol oil was obtained using 600 bars and $60^{\circ} \mathrm{C}$; these parameters were reduced to 200 bars and $40^{\circ} \mathrm{C}$ to obtain low oryzanol oil with a similar $25 \mathrm{~g} \cdot \mathrm{min}^{-1}$ flow rate and $150 \mathrm{~min}$ as duration of time. No change in fatty acid, wax of unsaponifaible contents of the two SFE extracted oils were detected so that SFE can profitably be applied in the extraction of $\mathrm{HO}$ and LO RBO as new functional ingredients of natural origin using an environmentally clean extraction technique that can be used by the food industry. However, LO seems to be economically better as it uses low pressure and temperature.

\subsection{Oxidative stability of rice bran oil extracted using SFE and soxhlet methods}

Oxidative stability (also known as the induction period) is a measurement of an oil or fat's resistance to oxidation. Because the process takes place through a chain reaction, the oxidation reaction has a period when it is relatively slow, before it suddenly speeds up. Oxidative stability is one of the most important indicators for maintaining the quality of edible oils. To date, many studies have been conducted to evaluate the oxidative stability of various seed oils.

TABLE 1. Unsaponifiable, oryzanol, wax and lipid classes of RBOs extracted by SFE and Soxhlet methods*

\begin{tabular}{lccccccc}
\hline Sample & $\begin{array}{c}\text { Unsaponifiable } \\
\text { matters }(\%)\end{array}$ & $\begin{array}{c}\gamma \text {-Oryzanol } \\
\left(\mathbf{m g} \cdot \mathbf{g}^{-1}\right)\end{array}$ & $\begin{array}{c}\text { Tocopherol } \\
\left(\mathbf{m} \cdot \mathbf{g}^{-1}\right)\end{array}$ & $\mathbf{W a x}(\mathbf{\%})$ & $\begin{array}{c}\text { Neutral lipid } \\
\left(\mathbf{g} \cdot \mathbf{g}^{-1}\right)\end{array}$ & $\begin{array}{c}\text { Glycolipid } \\
\mathbf{( g \cdot \mathbf { g } ^ { - 1 } )}\end{array}$ & $\begin{array}{c}\text { Phospholipid } \\
\left(\mathbf{g} \cdot \mathbf{g}^{-1}\right)\end{array}$ \\
\hline SFE HO & $8.2 \pm 0.2^{\mathrm{a}}$ & $7.7 \pm 0.3^{\mathrm{a}}$ & $3.2 \pm 0.3^{\mathrm{a}}$ & $0.45 \pm 0.1^{\mathrm{a}}$ & $0.97 \pm 0.01^{\mathrm{a}}$ & $0.03 \pm 0.1^{\mathrm{a}}$ & $0.01 \pm 0.1^{\mathrm{a}}$ \\
SFE LO & $5.2 \pm 0.1^{\mathrm{b}}$ & $6.3 \pm 0.2^{\mathrm{b}}$ & $2.6 \pm 0.3^{\mathrm{b}}$ & $0.47 \pm 0.1^{\mathrm{a}}$ & $0.95 \pm 0.01^{\mathrm{a}}$ & $0.03 \pm 0.1^{\mathrm{a}}$ & $0.01 \pm 0.1^{\mathrm{a}}$ \\
SOX & $4.7 \pm 0.1^{\mathrm{c}}$ & $4.7 \pm 0.2^{\mathrm{c}}$ & $4.0 \pm 0.1^{\mathrm{c}}$ & $0.32 \pm 0.1^{\mathrm{a}}$ & $0.70 \pm 0.4^{\mathrm{b}}$ & $0.01 \pm 0.1^{\mathrm{a}}$ & $0.06 \pm 0.1^{\mathrm{a}}$ \\
\hline
\end{tabular}

SFE HO: Supercritical fluid extraction high oryzanol; SFE LO: Supercritical fluid extraction low oryzanol; SOX: Soxhlet; *Values are means of three replicates \pm standard deviation. Means within columns with common superscript letters are not different $(P>0.05)$. 
TABLE 2. Fatty acids composition (weight \%) of RBOs extracted by SFE and Soxhlet methods*

\begin{tabular}{lrrr}
\hline Fatty acid & \multicolumn{1}{c}{ SFE HO } & \multicolumn{1}{c}{ SFE LO } & \multicolumn{1}{c}{ SOX } \\
\hline $14: 0$ & $0.6 \pm 0.01^{\mathrm{a}}$ & $0.5 \pm 0.01^{\mathrm{a}}$ & $0.6 \pm 0.01^{\mathrm{a}}$ \\
$16: 0$ & $16.4 \pm 0.05^{\mathrm{a}}$ & $16.7 \pm 0.04^{\mathrm{a}}$ & $16.7 \pm 0.05^{\mathrm{a}}$ \\
$16: 1 \mathrm{n}-7$ & $0.2 \pm 0.01^{\mathrm{a}}$ & $0.2 \pm 0.01^{\mathrm{a}}$ & $0.2 \pm 0.01^{\mathrm{a}}$ \\
$16: 1 \mathrm{n}-9$ & $0.1 \pm 0.01^{\mathrm{a}}$ & $0.1 \pm 0.01^{\mathrm{a}}$ & $0.1 \pm 0.01^{\mathrm{a}}$ \\
$18: 0$ & $2.1 \pm 0.02^{\mathrm{a}}$ & $2.2 \pm 0.02^{\mathrm{a}}$ & $2.5 \pm 0.03^{\mathrm{b}}$ \\
$18: 1 \mathrm{n}-9$ & $43.8 \pm 0.04^{\mathrm{a}}$ & $43.3 \pm 0.03^{\mathrm{a}}$ & $42.2 \pm 0.05^{\mathrm{a}}$ \\
$18: 1 \mathrm{n}-7$ & $0.9 \pm 0.01^{\mathrm{a}}$ & $1.0 \pm 0.02^{\mathrm{a}}$ & $0.9 \pm 0.01^{\mathrm{a}}$ \\
$18: 2 \mathrm{n}-6$ & $33.0 \pm 0.04^{\mathrm{a}}$ & $33.0 \pm 0.04^{\mathrm{a}}$ & $32.8 \pm 0.03^{\mathrm{a}}$ \\
$20: 1 \mathrm{n}-9$ & $0.8 \pm 0.02^{\mathrm{a}}$ & $0.9 \pm 0.02^{\mathrm{a}}$ & $0.9 \pm 0.02^{\mathrm{a}}$ \\
$18: 3$ & $1.3 \pm 0.02^{\mathrm{a}}$ & $0.0 \pm 0.01^{\mathrm{b}}$ & $0.0 \pm 0.01^{\mathrm{b}}$ \\
$20: 1 \mathrm{n}-7$ & $0.0 \pm 0.01^{\mathrm{a}}$ & $1.3 \pm 0.02^{\mathrm{b}}$ & $1.3 \pm 0.02^{\mathrm{b}}$ \\
SFA & $19.1 \pm 0.04^{\mathrm{a}}$ & $19.4 \pm 0.04^{\mathrm{a}}$ & $19.8 \pm 0.05^{\mathrm{b}}$ \\
MUFA & $44.9 \pm 0.1^{\mathrm{a}}$ & $46.8 \pm 0.04^{\mathrm{b}}$ & $45.6 \pm 0.05^{\mathrm{c}}$ \\
PUFA & $34.3 \pm 0.2^{\mathrm{a}}$ & $33.0 \pm 0.1^{\mathrm{b}}$ & $32.8 \pm 0.04^{\mathrm{c}}$ \\
\hline
\end{tabular}

For abbreviations, see Table 1 . *Values are means of three replicates \pm standard deviation. Values in the same row with different superscripts are significantly different $(p \leq 0.05)$. SFA Saturated fatty acid, MUFA Monounsaturated fatty acid, PUFA Polyunsaturated fatty acid.

\subsubsection{Peroxide value of different RBOs during storage}

$\mathrm{PV}$ is a measurement of the amount of peroxides formed in fats and oils through autoxidation and oxidation processes (Stier 2006). Generally, it is a measurement of the degree of initial oxidation of fats and oils. Measuring the peroxide value is wellestablished method for the determination of primary oxidation products in fats (Kulås and Ackman 2001). The peroxide values of SFE HO, SFA LO and SOX oils with and without BHA during storage for 42 days are shown in Table 3. Since RBO contains relatively high levels of unsaturated fatty acids (more than $77 \%$ ), oxidation can occur during the extraction and during post-harvest processing and storage. The addition of synthetic butylated hydroxyanisol (BHA) to these oils protects them against oxidation. Table 3 shows that the initial PVs of SOX, SFE HO, SFE LO are 1.8, 0.75 and $0.5 \mathrm{meq}$ $\mathrm{O}_{2} \cdot \mathrm{kg}^{-1}$ oil, respectively, the initial PV of SOX was higher than SFE, after storage for 42 days under successive heating at $70{ }^{\circ} \mathrm{C}$. The PV changed during storage and increased to $14.0,11.25$ and 10.25 meq $\mathrm{O}_{2} \cdot \mathrm{kg}^{-1}$ oil, respectively. After the addition of BHA the PVs were 13.3, 10.5 and $8.25 \mathrm{meq} \mathrm{O}_{2} \cdot \mathrm{kg}^{-1}$ oil respectively, indicating that BHA keeps the oil from oxidation. These results showed that the oxidative stability of RBO could be protected by extracting the oil using the SFE technique which produces stable oils.

\subsubsection{Free fatty acids of different RBOs during storage}

The free fatty acids (\%) of different RBOs during storage are shown in Table 4 . The FFA level of SOX (4.125 \pm 0.06$)$ was significantly higher than (3.1 and 3.57) that of the SFE HO, SFE LO samples at zero time, respectively. The FFA level increased to 23.04, 21.99 and 23.0 in SOX, SFE $\mathrm{HO}$ and SFE LO during 42 days of storage, respectively. These amounts decreased after the addition of BHA. The oils extracted by SFE showed low amounts of \% FFAs. These oils seem to be more stable than the oils extracted using Soxhlet method. The presence of natural antioxidants such as gamma oryzanol and tocopherol besides a high amount of unsaponifiable matters in the SFE oil can explain its high stability compared to the SOX oil.

\subsubsection{Conjugated dienes of different RBOs during storage}

The measurement of conjugated dienes is a useful index of the early stages of peroxidation in studies with pure lipids and isolated lipoproteins

TABLE 3. Peroxide value (meq O2/kg-1 oil) of rice bran oil extracted by SFE and Soxhlet methods with and without BHA during storage*

\begin{tabular}{lcccccc}
\hline Time (day) & SOX & SOX+BHA & SFE(HO) & SFE(HO)+BHA & SFE(LO) & SFE(LO)+BHA \\
\hline 0 & $1.8 \pm 0.4$ & $1.3 \pm 0.3$ & $0.75 \pm 0.2$ & $0.50 \pm 0.2$ & $0.50 \pm 0.2$ & $0.50 \pm 0.2$ \\
3 & $2.5 \pm 0.2$ & $2.1 \pm 0.2$ & $6.30 \pm 0.3$ & $4.0 \pm 0.3$ & $6.0 \pm 0.8$ & $5.0 \pm 0.4$ \\
7 & $9.8 \pm 0.2$ & $8.3 \pm 0.2$ & $7.5 \pm 0.5$ & $4.7 \pm 0.8$ & $6.7 \pm 0.7$ & $5.5 \pm 0.5$ \\
14 & $11.35 \pm 1.7$ & $10.5 \pm 1.5$ & $7.25 \pm 0.25$ & $6.0 \pm 1.0$ & $7.25 \pm 1.3$ & $6.25 \pm 0.7$ \\
21 & $12.0 \pm 1.25$ & $11.25 \pm 1.25$ & $7.50 \pm 1.5$ & $6.0 \pm 0.5$ & $8.0 \pm 1.5$ & $7.0 \pm 1.0$ \\
28 & $12.3 \pm 0.3$ & $11.8 \pm 0.7$ & $8.75 \pm 1.5$ & $7.5 \pm 0.2$ & $9.25 \pm 0.75$ & $7.5 \pm 0.5$ \\
35 & $13.5 \pm 0.5$ & $12.0 \pm 2.0$ & $9.50 \pm 0.6$ & $9.3 \pm 1.3$ & $10.0 \pm 0.05$ & $8.0 \pm 1.3$ \\
42 & $14.0 \pm 1.2$ & $13.3 \pm 2.3$ & $11.25 \pm 0.25$ & $10.5 \pm 0.1$ & $10.25 \pm 0.1$ & $8.25 \pm 0.8$ \\
\hline
\end{tabular}

For abbreviations, see Table 1 . *Values are means of three replicates \pm standard deviation. 
TABLE 4. Free fatty acid (\%) of rice bran oil extracted by SFE and Soxhlet methods during storage*

\begin{tabular}{lcccccc}
\hline Time (day) & SOX & SOX+BHA & SFE(HO) & SFE(HO)+BHA & SFE(LO) & SFE(LO)+BHA \\
\hline 0 & $4.13 \pm 0.06$ & $2.75 \pm 0.07$ & $3.10 \pm 0.28$ & $2.54 \pm 0.28$ & $3.57 \pm 0.09$ & $2.65 \pm 0.05$ \\
3 & $12.69 \pm 1.41$ & $11.28 \pm 2.82$ & $11.28 \pm 1.69$ & $11.28 \pm 0.56$ & $12.69 \pm 0.28$ & $10.01 \pm 0.14$ \\
7 & $12.97 \pm 0.10$ & $12.69 \pm 1.41$ & $12.4 \pm 0.10$ & $10.99 \pm 0.84$ & $20.17 \pm 0.43$ & $19.32 \pm 0.71$ \\
14 & $13.53 \pm 0.57$ & $12.97 \pm 0$ & $18.05 \pm 2.54$ & $18.76 \pm 5.2$ & $21.72 \pm 0.57$ & $21.15 \pm 0.56$ \\
21 & $18.33 \pm 1.40$ & $16.64 \pm 0.85$ & $18.33 \pm 1.41$ & $19.45 \pm 0.84$ & $22.42 \pm 0.99$ & $21.72 \pm 0.57$ \\
28 & $21.99 \pm 0.50$ & $21.42 \pm 0.56$ & $20.86 \pm 2.25$ & $20.02 \pm 0.84$ & $22.59 \pm 0.29$ & $21.98 \pm 1.27$ \\
35 & $21.99 \pm 0.50$ & $21.71 \pm 0.28$ & $21.24 \pm 0.55$ & $21.16 \pm 0.54$ & $22.88 \pm 0.36$ & $22.11 \pm 0.75$ \\
42 & $23.04 \pm 1.26$ & $21.78 \pm 2.26$ & $21.99 \pm 0.29$ & $21.25 \pm 1.41$ & $23.00 \pm 1.16$ & $22.34 \pm 0.50$ \\
\hline
\end{tabular}

For abbreviations, see Table 1. *Values are means of three replicates \pm standard deviation.

(Dekkers et al., 1996). Table 5 shows the conjugated dienes of the different RBOs extracted using the two different methods. In this table it can be seen that conjugated diene levels increased rapidly in RBOs between 0 and 42 days at both 234 and $270 \mathrm{~nm}$. SFE HO and SFE LO contained lower amounts of CD (0.55 and 0.675$)$ than that of SOX $(0.921)$ at $234 \mathrm{~nm}$ whose amounts were $0.602,0.603$ and 0.713 at $270 \mathrm{~nm}$, respectively. After storage for 42 days the conjugated dienes were significantly increased in SOX, SFE HO, and SFE LO to 1.143, 1.101 and 1.13 respectively at $234 \mathrm{~nm}$ and $1.438,1.255$ and 1.27 at $270 \mathrm{~nm}$, respectively. From Table 5 it is clear that SFE HO and SFE LO showed better stability than SOX under successive heating for 42 days and the addition of BHA decreased conjugated diene levels in all samples.

\subsubsection{TBAR levels in Different RBOs during Storage}

The change in TBAR levels $\left(\mu \mathrm{mol} \cdot \mathrm{g}^{-1}\right)^{2}$ in the different RBOs during storage is shown in Table 6 . The TBAR level increased significantly $(\mathrm{P}<0.001)$ from 0.37 to $1.32 \mu \mathrm{mol} \cdot \mathrm{g}^{-1}$ between day 0 and 42 days in SOX. These levels increased from 0.20 to 0.88 in SFE HO and from 0.32 to $0.86\left(\mu \mathrm{mol} \cdot \mathrm{g}^{-1}\right)^{2}$ in SFE LO, respectively. These results show that the oils extracted by SFE have better stability than SOX. The addition of BHA antioxidants to all samples

TABle 5. Conjugated dienes $(234 \mathrm{~nm}$ and $270 \mathrm{~nm})$ of rice bran oil extracted by SFE and Soxhlet methods during storage*

\begin{tabular}{|c|c|c|c|c|c|c|}
\hline Time (day) & SOX & SOX+BHA & SFE(HO) & SFE(HO)+BHA & SFE(LO) & SFE(LO)+BHA \\
\hline \multicolumn{7}{|l|}{$234 \mathrm{~nm}$} \\
\hline 0 & $0.921 \pm 0.20$ & $0.802 \pm 0.11$ & $0.550 \pm 0.03$ & $0.63 \pm 0.19$ & $0.675 \pm 0.006$ & $0.651 \pm 0.05$ \\
\hline 3 & $1.021 \pm 0.20$ & $0.864 \pm 0.03$ & $0.703 \pm 0.30$ & $0.688 \pm 0.30$ & $0.691 \pm 0.09$ & $0.656 \pm 0.05$ \\
\hline 7 & $1.025 \pm 0.02$ & $0.950 \pm 0.09$ & $0.779 \pm 0.12$ & $0.739 \pm 0.04$ & $0.764 \pm 0.07$ & $0.664 \pm 0.06$ \\
\hline 14 & $1.100 \pm 0.10$ & $1.060 \pm 0.11$ & $0.982 \pm 0.02$ & $1.00 \pm 0.11$ & $0.879 \pm 0.21$ & $0.731 \pm 0.11$ \\
\hline 21 & $0.937 \pm 0.18$ & $0.807 \pm 0.14$ & $1.045 \pm 0.09$ & $1.025 \pm 0.01$ & $1.079 \pm 0.11$ & $1.041 \pm 0.14$ \\
\hline 28 & $1.062 \pm 0.14$ & $0.992 \pm 0.09$ & $1.02 \pm 0.18$ & $0.992 \pm 0.08$ & $1.10 \pm 0.020$ & $1.105 \pm 0.17$ \\
\hline 35 & $1.106 \pm 0.17$ & $1.053 \pm 0.15$ & $1.08 \pm 0.11$ & $1.06 \pm 0.02$ & $1.100 \pm 0.02$ & $1.107 \pm 0.11$ \\
\hline 42 & $1.143 \pm 0.24$ & $1.065 \pm 0.13$ & $1.101 \pm 0.18$ & $1.08 \pm 0.01$ & $1.130 \pm 0.05$ & $1.126 \pm 0.09$ \\
\hline \multicolumn{7}{|l|}{$270 \mathrm{~nm}$} \\
\hline 0 & $0.602 \pm 0.12$ & $0.602 \pm 0.11$ & $0.603 \pm 0.40$ & $0.646 \pm 0.30$ & $0.713 \pm 0.04$ & $0.715 \pm 0.05$ \\
\hline 3 & $0.752 \pm 0.15$ & $0.655 \pm 0.05$ & $0.820 \pm 0.20$ & $0.792 \pm 0.23$ & $0.890 \pm 0.04$ & $0.763 \pm 0.09$ \\
\hline 7 & $1.081 \pm 0.16$ & $0.790 \pm 0.20$ & $0.851 \pm 0.21$ & $0.738 \pm 0.07$ & $0.950 \pm 0.07$ & $0.900 \pm 0.21$ \\
\hline 14 & $1.253 \pm 0.12$ & $1.168 \pm 0.08$ & $1.253 \pm 0.04$ & $1.080 \pm 0.13$ & $1.07 \pm 0.11$ & $0.920 \pm 0.07$ \\
\hline 21 & $1.266 \pm 0.29$ & $0.942 \pm 0.08$ & $1.095 \pm 0.04$ & $1.080 \pm 0.80$ & $1.169 \pm 0.17$ & $0.940 \pm 0.01$ \\
\hline 28 & $1.266 \pm 0.06$ & $1.199 \pm 0.04$ & $1.176 \pm 0.02$ & $1.157 \pm 0.01$ & $1.180 \pm 0.11$ & $1.155 \pm 0.11$ \\
\hline 35 & $1.318 \pm 0.08$ & $1.165 \pm 0.04$ & $1.239 \pm 0.11$ & $1.179 \pm 0.02$ & $1.253 \pm 0.13$ & $1.236 \pm 0.25$ \\
\hline 42 & $1.438 \pm 0.04$ & $1.299 \pm 0.03$ & $1.255 \pm 0.07$ & $1.197 \pm 0.25$ & $1.270 \pm 0.36$ & $1.246 \pm 0.13$ \\
\hline
\end{tabular}

For abbreviations, see Table 1. *Values are means of three replicates \pm standard deviation. 
TABLE 6. TBAR $\left(\mu \mathrm{mol} \cdot \mathrm{g}^{-1}\right)^{2}$ of rice bran oil extracted by SFE and Soxhlet methods during storage*

\begin{tabular}{lcccccc}
\hline Time (day) & SOX & SOX+BHA & SFE(HO) & SFE(HO)+BHA & SFE(LO) & SFE(LO)+BHA \\
\hline 0 & $0.370 \pm 0.005$ & $0.310 \pm 0.010$ & $0.207 \pm 0.002$ & $0.203 \pm 0.010$ & $0.31 \pm 0$ & $0.300 \pm 0.010$ \\
3 & $0.606 \pm 0.030$ & $0.617 \pm 0.010$ & $0.556 \pm 0.003$ & $0.598 \pm 0.005$ & $0.577 \pm 0.002$ & $0.445 \pm 0.007$ \\
7 & $0.795 \pm 0.004$ & $0.690 \pm 0.020$ & $0.706 \pm 0.040$ & $0.594 \pm 0.016$ & $0.661 \pm 0.05$ & $0.560 \pm 0.108$ \\
14 & $0.897 \pm 0.02$ & $0.705 \pm 0.080$ & $0.732 \pm 0.080$ & $0.689 \pm 0.060$ & $0.639 \pm 0.09$ & $0.570 \pm 0.050$ \\
21 & $0.73 \pm 0.18$ & $0.820 \pm 0.020$ & $0.740 \pm 0.020$ & $0.71 \pm 0.030$ & $0.860 \pm 0.01$ & $0.771 \pm 0.020$ \\
28 & $0.913 \pm 0.004$ & $0.850 \pm 0.010$ & $0.786 \pm 0.070$ & $0.738 \pm 0.050$ & $0.899 \pm 0.08$ & $0.738 \pm 0.050$ \\
35 & $0.94 \pm 0.008$ & $0.880 \pm 0.070$ & $0.881 \pm 0.220$ & $0.729 \pm 0.005$ & $0.916 \pm 0.007$ & $0.864 \pm 0.010$ \\
42 & $1.32 \pm 0.2$ & $1.03 \pm 0.010$ & $0.946 \pm 0.070$ & $0.808 \pm 0.110$ & $0.96 \pm 0.05$ & $0.870 \pm 0.040$ \\
\hline
\end{tabular}

For abbreviations, see Table 1. *Values are means of three replicates \pm standard deviation.

was effective in reducing the formation of secondary oxidation products, and thus increasing the oxidative stability.

\subsubsection{P-anisidine value of rice bran oil extracted by SFE and Soxhlet methods during storage}

The $p$-anisidine values (p-AV) of rice bran oil extracted by the SFE and Soxhlet methods during storage are shown in Table 7. The successive heating of RBOs (at $70{ }^{\circ} \mathrm{C}$ for 42 days) with and without BHA leads to autoxidation and formation of primary products that decomposed readily and formed aldehydes, ketones and alcohols as secondary products. As p-AV is a more meaningful test for the assessment of the oil's quality during heating than the PV, it was used here because it measures the secondary products of oxidation reactions (Mariod et al., 2010). Using SFE as a method of extraction gave products rich in natural antioxidants that inhibited the formation of the secondary products in comparison with the Soxhlet method; the amount of secondary products formed seems to be smaller than that formed in the SOX samples (Table 7). The P-AVs of SOX, SFE HO and SFE LO at day zero without and with BHA were 0.107, 0.094, 0.039, $0.03,0.042$ and 0.032 respectively; these amounts increased rapidly to $0.489,0.476,0.121,0.11,0.10$, and 0.10 respectively.

\subsubsection{Tocopherols of rice bran oil extracted by SFE and soxhlet methods during storage}

Table 8 illustrates the decrease in the amounts of the total tocopherol contents $\left(\mathrm{mg} \cdot \mathrm{g}^{-1}\right)$ of SOX and SFE HO and SFE LO with increasing storage time. Within 42 days more than $46 \%$ of the initial amount of tocopherols was degraded in SOX, while in SFE HO and SFE LO only $31 \%$ and $42 \%$ of the initial tocopherols was degraded, respectively. The addition of synthetic BHA normally retards this degradation in all samples. In spite of the higher amount of total tocopherols at the beginning of the storage period (zero day), the degradation of tocopherols occurred significantly $(P<0.05)$ faster in SOX than in SFE, where part of the initial tocopherols was still available after 42 days of storage. It is possible that, in addition to oryzanol and tocopherols, RBO contains other anti-oxidative active components that retard the degradation of the tocopherols and increase the shelf-life of the oil. Previous research has shown the degradation of tocopherols in the storage of edible oils (Chotimarkorn et al., 2005, Player et al., 2006) due to autoxidation.

TABle 7. P-anisidine value of rice bran oil extracted by SFE and Soxhlet methods during storage*

\begin{tabular}{lcccccc}
\hline Time (day) & SOX & SOX+BHA & SFE(HO) & SFE(HO)+BHA & SFE(LO) & SFE(LO)+BHA \\
\hline 0 & $0.107 \pm 0.003$ & $0.094 \pm 0.002$ & $0.039 \pm 0.002$ & $0.030 \pm 0.003$ & $0.042 \pm 0.002$ & $0.032 \pm 0.010$ \\
3 & $0.115 \pm 0.010$ & $0.104 \pm 0.006$ & $0.045 \pm 0.001$ & $0.047 \pm 0.003$ & $0.049 \pm 0.020$ & $0.056 \pm 0.010$ \\
7 & $0.135 \pm 0.160$ & $0.109 \pm 0.001$ & $0.048 \pm 0.001$ & $0.046 \pm 0.010$ & $0.052 \pm 0.010$ & $0.054 \pm 0.010$ \\
14 & $0.143 \pm 0.001$ & $0.125 \pm 0.002$ & $0.068 \pm 0.005$ & $0.051 \pm 0.007$ & $0.065 \pm 0.005$ \\
21 & $0.390 \pm 0.004$ & $0.223 \pm 0.010$ & $0.070 \pm 0.008$ & $0.057 \pm 0.017$ & $0.092 \pm 0.005$ \\
28 & $0.400 \pm 0.004$ & $0.378 \pm 0.020$ & $0.090 \pm 0.020$ & $0.067 \pm 0.010$ & $0.103 \pm 0.020$ \\
35 & $0.424 \pm 0.006$ & $0.416 \pm 0.020$ & $0.108 \pm 0.020$ & $0.100 \pm 0.005$ & $0.112 \pm 0.002$ & $0.09 \pm \pm 0.006$ \\
42 & $0.489 \pm 0.010$ & $0.476 \pm 0.020$ & $0.121 \pm 0.030$ & $0.110 \pm 0.050$ & $0.100 \pm 0.002$ & $0.082 \pm 0.002$ \\
\hline
\end{tabular}

For abbreviations, see Table 1. *Values are means of three replicates \pm standard deviation. 
TABLE 8. Tocopherol $\left(\mathrm{mg} \cdot \mathrm{g}^{-1}\right)$ of rice bran oil extracted by SFE and Soxhlet methods during storage*

\begin{tabular}{lcccccc}
\hline Time (day) & SOX & SOX+BHA & SFE(HO) & SFE(HO)+BHA & SFE(LO) & SFE(LO)+BHA \\
\hline 0 & $4.13 \pm 0.1$ & $4.13 \pm 0.2$ & $3.2 \pm 0.3$ & $3.2 \pm 0.2$ & $2.6 \pm 0.2$ & $2.6 \pm 0.2$ \\
3 & $2.78 \pm 0.1$ & $3.9 \pm 0.3$ & $3.1 \pm 0.2$ & $3.1 \pm 0.2$ & $2.5 \pm 0.1$ & $2.5 \pm 0.2$ \\
7 & $2.21 \pm 0.2$ & $3.8 \pm 0.2$ & $3.0 \pm 0.1$ & $3.1 \pm 0.1$ & $2.3 \pm 0.1$ & $2.4 \pm 0.1$ \\
14 & $3.15 \pm 0.3$ & $3.6 \pm 0.2$ & $3.0 \pm 0.1$ & $3.0 \pm 0.1$ & $2.1 \pm 0.1$ & $2.3 \pm 0.1$ \\
21 & $2.79 \pm 0.2$ & $3.2 \pm 0.1$ & $2.9 \pm 0.2$ & $2.9 \pm 0.3$ & $2.0 \pm 0.1$ & $2.2 \pm 0.1$ \\
28 & $2.56 \pm 0.1$ & $3.1 \pm 0.1$ & $2.7 \pm 0.1$ & $2.8 \pm 0.2$ & $1.8 \pm 0.1$ & $2.0 \pm 0.1$ \\
35 & $2.46 \pm 0.1$ & $2.8 \pm 0.1$ & $2.5 \pm 0.1$ & $2.7 \pm 0.1$ & $1.6 \pm 0.1$ & $1.9 \pm 0.1$ \\
42 & $2.21 \pm 0.1$ & $2.7 \pm 0.1$ & $2.4 \pm 0.1$ & $2.6 \pm 0.1$ & $1.5 \pm 0.1$ & $1.8 \pm 0.1$ \\
\hline
\end{tabular}

For abbreviations, see Table $1 .{ }^{*}$ Values are means of three replicates \pm standard deviation.

\section{CONCLUSIONS}

To obtain the HO from SFE the pressure was 600 bars and the temperature was $60{ }^{\circ} \mathrm{C}$. Meanwhile, to obtain the LO the pressure was 200 bars and temperature was $40{ }^{\circ} \mathrm{C}$. The flow rate and duration of time to extract $\mathrm{HO}$ and $\mathrm{LO}$ were similar with $25 \mathrm{~g} \cdot \mathrm{min}^{-1}$ of flow rate and 150 mins duration of time. The present work indicates the importance of using SFE in the edible oil extraction process. The extraction of RBO using the SFE technique produces oils with high oxidative stability and free of solvents. SFE can be adjusted to produce high or low oryzanol RBOs and as oryzanol is an effective antioxidant these oils can be stored for up to 42 days under successive heating and show better stability than oils extracted by the Soxhlet conventional method. Peroxide, TBARS, CD and $p$-anisidine values were reliable methods that can be used to determine peroxidation in oils containing various concentrations of oryzanol (SFE HO, and SFE LO) as well as SOX. The addition of BHA to oils can decrease lipid peroxidation and increase oil stability. SFE oils tolerate lipid peroxidation during long storage periods due to their minor components. Therefore, these oils can provide potential sources of natural antioxidants and can be used in the inhibition of lipid oxidation in nutraceuticals and functional foods.

\section{REFERENCES}

AOCS. 1998. Official Methods and Recommended Practices of the American Oil Chemists' Society, 4th edn., AOCS Press, Champaign, IL.

Anwar F, Anwer T, Mahmood Z. 2005. Methodical characterization of rice (Oryza sativa) bran oil from Pakistan. Grasas Aceites. 56, 125-134.

Balachandran C, Mayamol PN, Thomas S, Sukumar D, Sundaresan A, Arumughan C. 2008. An ecofriendly approach to process rice bran for high quality rice bran oil using supercritical carbon dioxide for nutraceutical applications. Biores Technol. 99, 2905-2912.

Bruhl L, and Matthaus B. 1999. Extraction of oilseeds by SFE a comparison with other methods for the determination of the oil content. J. Anal. Chem. 364, 631-634.
Chatha SAS, Anwar F, Manzoor M, Bajwa J. 2006. Evaluation of the antioxidant activity of rice bran extracts using different antioxidant assays. Grasas Aceites 57, 328-335.

Chotimarkorn C, Ohshima T, Ushio, H. 2005. Fluorometric and fluorescent image analysis methods for determination of lipid hydroperoxides in oil models with 3-perylene diphenylphosphine (3-PeDPP). J. Agri. Food Chem. 53, 7361-7366.

Cicero AFG, and Gaddi, A. 2001. Rice bran oil and gammaoryzanol in the treatment of hyperlipoproteinaemias and other conditions. Phytoth. Res. 15, 277-289.

Dekkers J, van Doornen L, Kemper H. 1996. The role of antioxidant vitamins and enzymes in the prevention of exerciseinduced muscle damage. Sports Med. 21, 213-38.

Duvernay WH, Assad JM, Sabliov CM, Lima M, Xu Z. 2005. Microwave Extraction of Antioxidant Components from Rice Bran. Pharm. Eng. 25, 1-5.

Hubbard JD, Downing JM, Ram MS, Chung OK. (2004). Lipid extraction from wheat flour using supercritical fluid extraction. Cereal Chem. 81, 693-698.

Iqbal S, Bhanger MI, Anwar F. 2005. Antioxidant properties and components of some commercially available varieties of rice bran in Pakistan. Food Chem. 93, 265-272.

Kulås E, and Ackman R. G. 2001. Different Tocopherols and the Relationship between Two Methods for Determination of Primary Oxidation Products in Fish Oil. J. Agric. Food Chem. 49, 1724-1729.

Mariod AA, Ibrahim RM, Ismail M, Ismail N. 2010. Antioxidant Activity of the Phenolic Leaf Extracts from Monechma ciliatum in Stabilization of Corn Oil. J. Am. Oil Chem. Soc. 87, 35-43.

Mariod AA, Matthäus B, Eichner K, Hussein IH. 2006. Antioxidant activity of extracts from Sclerocarya birrea kernel oil cakes. Grasas Aceites 57, 361-366.

Mariod AA, Adamu HA, Ismail M, Ismail N, 2010. Antioxidative effects of stabilized and unstabilized defatted rice bran methanolic extracts on the stability of rice bran oil under accelerated conditions. Grasas Aceites, 61, 409-415.

Mishra R, Sharma HK, Sengar G. 2012. Quantification of rice bran oil in oil blends. Grasas Aceites 63,53-60.

Nam SH, Choi SP, Kang MY, Kho HJ, Kozukue N, Griedman M. 2006. Antioxidative activities of bran extracts from twenty one pigmented rice cultivars. Food Chem. 94, 613-620.

Patel PM. 2005. Supercritical fluid extraction of rice bran with adsorption on rice hull ash. PhD Thesis, Louisiana State University, Louisiana, USA.

Player ME, Kim HJ, Lee HO, Min DB. 2006. Stability of $\alpha-, \gamma$, or $\delta$ - tocopherol during soybean oil oxidation. J. Food Sci. 71, C456-C460

Pietta PG. 2000. Flavonoids as antioxidants. J. Nat. Prod. 63, 1035-1042.

Perretti G, Miniati E, Montanari L, Fantozzi P. 2003. Improving the value of rice by-products by SFE J. Supercrit. Fluid. 26, 63-71. 
Renuka Devi, R, Arumughan C. 2007. Phytochemical characterization of defatted rice bran and optimization of a process for their extraction and enrichment. Biores. Technol. 98, 3037-3043.

Rukmini C, and Raghuram TC. 1991. Nutritional and biochemical aspects of the hypolipidemic action of rice bran oil: A review. J. Am. Col. Nutr. 10, 593.

Rogers EJ, Rice SM, Nicolosi RJ, Carpenter DR., McClelland CA, Romancyzk LJ. 1993. Identification and quantification of $\gamma$-oryzanol components and simultaneous assessment of tocols in rice bran oil. J. Am. Oil Chem. Soc. 70, 301-307.

Shahid I, Bhanger MI, Farooq A. 2005. Antioxidant properties and components of some commercially available varieties of rice bran in Pakistan. Food Chem. 93, 265-272.

Shahidi F, Desilva C, Amarowicz R. 2003. Antioxidant activity of extracts of defatted seeds of niger (Cuizotia abyssinica). J. Am. Oil Chem. Soc. 80, 443-450.

STATGRAPHICS ${ }^{\circledR}$. 1985-1989. Statgraphics Statistical Graphics Systems, Version 4.0, STSC Inc. \& Statistical Graphics Cooperation, Rockville, MD.

Stier RF. 2001. The measurement of frying oil quality and authenticity. In Rossell, J. B. (ed.). Frying: Improving Quality. CRC Press Woodhead Publishing Limited, Cambridge, England, pp. 165-178. 